\title{
Challenges and Countermeasures of Chinese College English Teachers' Self-Development-Taking Shanghai Area as an Example
}

\author{
Bingtian Zhang
}

\begin{abstract}
College English is a required course for all non-English-major students in China. The new developing circumstances in modern China have made a claim for better-informed College English teachers. With the aid of the questionnaires, the challenges of Chinese College English teachers in their self-development are analyzed and the countermeasures are also suggested.
\end{abstract}

Index Terms-Challenge, College English teacher, countermeasure, self-development.

\section{INTRODUCTION}

As the process of globalization is accelerating and the world today is becoming increasingly competitive, English learning meets the demand of self-development and social progress. English is the most important international language and English language skills are also essential to students of the 21st century. College English (hereinafter referred to as CE) is a compulsory basic course for all non-English-major students of Chinese colleges and universities throughout the stage of higher education. Released in 2007 by the Ministry of Education of the People's Republic of China, College English Curriculum Requirements [1] clearly defined that the goal of CE teaching is to develop the students' comprehensive English language ability, especially listening and speaking skills, so that students can use English effectively in future work and other social activities. These requirements are a momentum for CE teachers in China, but they certainly have brought more pressure and challenges. As G. Xin concluded in [2], Chinese $\mathrm{CE}$ teachers are actually the main force and trial pioneers of the CE teaching reform, and a key factor to improve students' English proficiency. Therefore, the self-development of Chinese CE teachers has increasingly caught the eye and been brought to the forefront.

\section{ThE SURVEY AND DATA ANALYSIS}

\section{A. Subject of the Survey and Research Method}

The subject of the survey was CE teachers working in southwestern Shanghai's Songjiang University Town where seven universities are located. Altogether 350 questionnaires were evenly distributed in these universities and 343 of them

Manuscript received November 5, 2012; revised January 16, 2013.

Bingtian Zhang is with the School of Fundamental Studies, Shanghai University of Engineering Science, Shanghai, 201620 P. R. China (e-mail: christian_10@sohu.com). were resumed. The questions listed in the questionnaire were about the pressure they feel in their teaching, their English language proficiency and approaches to improving English skills, their use of modern multimedia facilities, their knowledge of contemporary English applied linguistic theories, and their opinion on the significance of scientific research, etc.

\section{B. Data Analysis}

The collected data are analyzed and the results are shown in Table I below.

TABLE I: RESULTS OF THE ANALYSIS

\begin{tabular}{|c|c|c|}
\hline Categories & Number of Teachers & Percentage of 343 \\
\hline $\begin{array}{c}\text { Great Working } \\
\text { Pressure }\end{array}$ & 256 & $75 \%$ \\
\hline $\begin{array}{c}\text { Excellent Command } \\
\text { of English }\end{array}$ & 168 & $49 \%$ \\
\hline $\begin{array}{c}\text { Familiar with Modern } \\
\text { English Teaching } \\
\text { Theories }\end{array}$ & 209 & $41 \%$ \\
\hline $\begin{array}{c}\text { Skillful Use of } \\
\text { Multimedia Facilities }\end{array}$ & 140 & $53 \%$ \\
\hline $\begin{array}{c}\text { Engaged in Scientific } \\
\text { Research }\end{array}$ & 182 & $61 \%$ \\
\hline
\end{tabular}

Judging from the results of the analysis, we can see that the vast majority of $\mathrm{CE}$ teachers in Shanghai believe they are confronted with increasing pressures and challenges, mainly reflected in the following aspects:

1) As is demonstrated in Table I, merely $49 \%$ of the $343 \mathrm{CE}$ teachers in Shanghai claimed excellent command of English while the English proficiency of the rest was barely satisfactory. A. Jia conformed in [3] that for College English education in China, the English proficiency of $\mathrm{CE}$ teachers is of key importance to enhancing the overall English teaching levels. However, because the majority of Chinese CE teachers receive their language education in China and most of their instructors are Chinese teachers; their basic English language skills are generally not perfect. Their English pronunciation is not accurate enough and their vocabulary in most cases can hardly meet their needs in conversations since they have picked up their vocabulary from books and magazines, which makes it an impossible task to speak fluent idiomatic English. In addition, quite a large part of Chinese CE teachers no longer insist on enhancing their English level. Few of them are willing to polish their English by listening to the BBC or VOA English broadcasts, watching CNN or CCTV-9 (China's national English Channel) English programs regularly. They rarely read English 
newspapers, magazines or English classics, let alone writing in English or doing translation. Language fossilization is very common among Chinese CE teachers.

2) Table I exposes that $61 \%$ of the $343 \mathrm{CE}$ teachers in Shanghai are familiar with modern English teaching theories, which means as many as $39 \%$ of them generally ignore them. As a matter of fact, students are not satisfied with the teaching methods of Chinese CE teachers. In the eye of most Chinese college students, CE classes are dull and dreary; the teachers' teaching methods are rather monotonous. When attending elementary and secondary schools, the majority of Chinese CE teachers were spoon-fed, the most traditional Chinese teaching practice supplemented with the boring grammar-translation method. Consequently, our Chinese CE teachers are unconsciously or subconsciously influenced by the impact of their education, thus making the traditional blackboard-and-chalk teaching methods passed on from generation to generation. Meanwhile, due to the increasing college enrollment in recent years, Chinese CE teachers' workload has surged. As a matter of fact, many young teachers who have just graduated from university took the responsibility of teaching the undergraduate students English even though they were quite short of systematic training or relevant working experience, which inevitably led to students' complaint. What's more, most of Chinese CE teachers are not expert at language acquisition theories and language teaching theories; their reflections on teaching practice and related scientific research are not sufficient. This has also caused the aimlessness of many Chinese CE teachers' teaching practice which in turn results in students' dissatisfaction.

3) As is shown in Table I, only $41 \%$ of the 343 CE teachers in Shanghai declared that they were skilled at taking full advantage of modern multimedia technology. Chinese students are generally tired of traditional teaching media featuring blackboard and chalk. The superiority of multimedia-aided teaching lies in relieving the contradiction between increasing teaching tasks and reduced class hours. The applications of multimedia in class can vividly express the content of teaching to stimulate students' enthusiasm for learning, facilitate the switch of the teachers' role from spoon-feeders to class organizers and facilitators, and help teachers adapt to the new mode of modern English education. However, because of the lack of computer-related education and the neglect of self-improvement, quite a large number of Chinese CE teachers are unable to operate a computer or use certain software skillfully so that many English teachers prefer to buy courseware available in market rather than make it by themselves. Virtually for most Chinese CE teachers, multimedia devices are used to play movies or video clips and act as the whiteboard without having to use markers, significantly reducing the effectiveness of multimedia. Effective use of multimedia teaching facilities is supposed to extend advanced educational philosophy vividly and enrich the teaching contents of a class visually. Therefore, it would be a sheer waste of teaching resources if multimedia facilities just served as decorations and Chinese CE teachers continued to fill "new wine in old bottles" in their teaching practice.

4) From Table I, it can be seen that CE teachers in Shanghai are rather inactive in doing scientific research. Just $53 \%$ of the $343 \mathrm{CE}$ teachers are engaged in continuous research work. Unlike traditional teachers who just did teaching work, university educators also shoulder the important task of scientific research? However, on the one hand, the research capacity of the English teachers is generally incompetent on account of their educational background; on the other hand, they are not yet aware of the importance of the research capacity to their own self-development. Research paper writing, the essence of which is the practice, reinforcement and improvement of the research capacity, is the most effective approach to self-development. A significant proportion of Chinese $\mathrm{CE}$ teachers have started to teach undergraduate courses right after obtaining their Bachelor's degree, and never had a systematic study of scientific research methods, which is another reason for their incompetence in doing scientific research.

\section{COUNTERMEASURES OF CHINESE CE TEACHERS IN THEIR SELF-DEVELOPMENT}

Through an investigation, M. Dai and X. Zhang concluded in [4] that the qualified $C E$ teachers should have the following qualities: perfect language skills in English; master the theories of English education, especially applied linguistics theories; familiar with the students' psychological conditions; well-informed in Chinese and Western cultures; proficient in using multimedia and other computer-aided teaching methods. Apparently, there exists a huge gap between the ideals and the status quo, which calls for more efforts in self-enhancement.

In recent years, owing to the huge number of Chinese CE teachers and the limitation of training approaches, training resources as well as funds, very few government- or school-sponsored on-the-job training activities aiming at perfecting English teaching methods and sharing teaching experience have been offered to Chinese CE teachers except the annual training by the Foreign Language Teaching and Research Press (FLTRP) in Beijing and Shanghai Foreign Language Education Press (SFLEP) which usually last for just a couple of days during the winter and summer vacations. Nevertheless, as the main body of the CE teaching and the main force of the CE research in China, CE teachers should admit their inadequacy, identify the existing gaps and spontaneously choose a different path of self-development according to their specific needs.

\section{A. Make Efforts to Maintain and Improve English Language Skills.}

To maintain and continue to improve their proficiency in English will be a task for all Chinese CE teachers throughout their whole career. Specific practices are as follows: First, take the way of self-improvement. Although as the saying 
goes that to teach is to learn, Chinese CE teachers, as foreign language learners, still need to consciously do a lot of reading and writing, listen to English recordings and watch English programs constantly to polish their English language skills. With English language itself developing and evolving each single day, all Chinese English learners, particularly CE teachers, have to keep pace with times. They can not rest on our laurels holding out the obsolete knowledge picked up in schools many years ago. Second, attend short-term language training or do research as a visiting scholar in English-speaking countries. Now a lot of Chinese colleges and universities send English teachers to English-speaking countries for short-term training or taking refresher courses during summer or winter vacations regularly, which can not only increase their knowledge, widen their horizons, experience the local culture of English-speaking countries, but also improve the oral communicative competence. In addition, the Shanghai Municipal Education Commission has begun to subsidize visiting scholars selected from local universities to do research in overseas countries since 2011 [5]. CE teachers should seize opportunities for involvement. Finally, set up spoken English teams among Chinese CE teachers. For those universities with foreign teachers, Chinese English teachers should take the initiative to routinely communicate with foreign teachers and make friends with them, which can maintain and improve their language skills. But for those schools without overseas teachers, Chinese English teachers should set up language teams among colleagues to improve their language proficiency by launching group work activities on a regular basis. Anyway, English language skills are the basis for any English study, teaching and research activities. M. Hu from Beijing's Renmin University denounced the trend of concentrating on developing new English teaching theories while neglecting sharpening their basic language skills in college English education [6].

\section{B. Learn the Latest Theories of Modern English Education, Improve Teaching Methods.}

Training of foreign language teachers is a top priority for the development of foreign language education in China. And it has become imperative for our foreign language teachers to keep up with the latest theories and practices of modern English applied linguistics. The majority of Chinese English teachers lack theoretical training, especially for Chinese CE teachers. Feasible practices to improve their theoretical accomplishments are as follows: First, consult the experts at home and abroad. Now almost all well-known English experts' e-mail addresses can be found on university portals. The experts at home and abroad are a valuable resource for language theoretical studies and they would usually enthusiastically help and guide the new scholars in their particular field of research; Opportunities to participate in the famous lectures and international conferences should never be missed, where young scholars can ask the experts for advice if they meet with any ambiguity in their research. Second, read relevant masterpieces in applied linguistics. Since 1999, China's major publishing houses have continually introduced five sets of high-quality original English books concerning contemporary Western teaching theories and practices. These series of classics have provided adequate and innovative source of teaching theories for the new scholars. Although we can hardly copy those theories in Chinese classrooms, there is a great significance for reference. With the guidance of the latest language acquisition theories, Chinese CE teachers may take care of our local practice with an international perspective.

\section{Cultivate the Abilities of Using Modern Means of Education, Especially the Ability to Use Multimedia Technology.}

Modern means of education, especially multimedia technology has had a profound influence on the traditional concepts of education, teaching mode and teachers' roles. With the large-scale development of higher education in China, the implementation of multimedia-aided teaching is not only a trend but also a brand-new educational philosophy. Therefore, the teaching management departments in universities should shoulder the responsibilities of promoting multimedia-aided teaching, making scientific and feasible countermeasures to ensure the general improvement of the quality of the multimedia teaching. To this end, the CE teachers should actively participate in the multimedia teaching technology training to understand and master the theories and skills of multimedia teaching system. The contents of the multimedia-aided training should include: modern English teaching theories; application of multimedia teaching equipments; courseware production; how to handle the relationship between man, hardware and software correctly; multimedia class tips, etc. Meanwhile, Chinese universities tend to publicize an open multimedia courseware making guidance e-mail address on their portals, where $\mathrm{CE}$ teachers may consult the problems in the making of multimedia courseware. In addition, CE teachers can also participate in seminars and tutorial classes about multimedia production or software applications so as to perfect their skills.

\section{Participate in Scientific Research Which in Turn Supports and Guides Teaching.}

The research work is the weakest link in the self-development of Chinese CE Teachers. Under the current academic evaluation system in China, a lot of $\mathrm{CE}$ teachers bend themselves to the promotion of their technical titles by doing research and getting papers published in academic journals; for those who do not care much about the technical titles, research work is just dispensable to their self-development. Admittedly, the objective conditions of the time, energy, and other restrictions can not be denied, but in the long run, the lack of research capabilities and preparation for the future will have negative impact on their own self-development as China is aiming at becoming a first-rate scientific and technological power by 2020 . Therefore, on the one hand, Chinese $\mathrm{CE}$ teachers might carry out teaching-based researches. In fact, there are too many things worthy of study, such as the mode of English teaching, the setup of college English curriculum, CE autonomous learning issues, CE teachers' self-development, and so on. On the other hand, CE teachers should apply for doing more research projects. At the moment, all universities, various educational institutions, local governments and the State 
Ministry of Education provide a variety of research projects every year. Each process of project application is also a process of learning and enhancement. And, through the completion of the project, CE teachers can theorize and then justify their teaching practice which conversely helps perfect their findings.

\section{E. Exchange Experience with Colleagues and Promote Common Development.}

CE teachers should frequently exchange experience in teaching and research work, which will not only improve their teaching ability, but also strengthen their mutual understanding and recognition, and bring the joy and satisfaction of the work. The ways of exchanging experience with colleagues are as follows: First, participate in the teaching competition. Through competing with each other and sitting in on each other's class, colleagues may have an easy and quick access to some fresh information and new style in English teaching, which is time-saving and efficient. Second, join class preparation groups and scientific research team. By collectively preparing for classes and jointly compiling high-quality teaching materials, CE teachers may share lots of theoretical and practical knowledge around teaching. As for scientific research, CE teachers will possess more opportunities of doing scientific projects if they are members of widely-recognized research groups. Finally, as suggested by G. Xin in [2], CE teachers may attend academic conferences and join professional organizations. For university educators, academic exchanges may broaden our theoretical vision and foster our ability of innovation. Participating in academic conferences and joining professional organizations enable Chinese CE teachers to exchange ideas and to establish contacts with domestic and even overseas counterparts.

\section{REFERENCES}

[1] Ministry of Education of the People's Republic of China. (July 2007) College English Curriculum Requirements. [Online]. pp. 1. Available: http://www.moe.gov.cn/publicfiles/business/htmlfiles/moe/moe_1846/ 201011/xxgk_110825.html.

[2] G. Xin, "On in-service college ELT teachers' self-directed development," Foreign Language Teaching Abroad, no. 3, pp. 18-24, Aug. 2006.

[3] A. Jia, "Literature review of foreign language teacher education and professional development," Foreign Language World, General Serial vol. 105, no.1, pp. 61-66, February 2005.

[4] M. Dai and X. Zhang, "An investigation of English teacher qualities in colleges and universities," Journal of PLA University of Foreign Languages, vol. 27, no. 2, pp. 42-46, March 2004.

[5] Shanghai Municipal Education Commission. (September 2011). On the disclosure of candidate list of the "Teachers' professional development project in 2011" for Shanghai university teachers' training. [Online]. pp. $1 . \quad$ Available: http://www.shmec.gov.cn/html/xxgk/201109/406112011012.php.

[6] M. Hu, "Personal experiences of foreign language learning and teaching," Journal of Foreign Languages, General Serial, vol. 141, no. 5, pp. 2-10, September 2002.

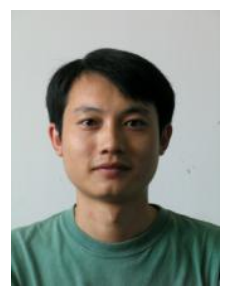

Bingtian Zhang was born in Shenyang, Liaoning province, P. R. China on December 22, 1978. He studied English language and literature in Shandong University, Jinan, Shandong Province, P. R. China from 1997 to 2001 and obtained his Bachelor's degree in July, 2001. After that, he pursued his study in foreign linguistics and applied linguistics in Dalian Maritime University, Dalian, Liaoning province, P. R. China and obtained his Master's degree in April, 2004 Now, he is the DIRCTOR of the Dean's Office, also an ENGLISH TEACHER of the School of Fundamental Studies, Shanghai University of Engineering Science, Shanghai, P. R. China. His research interests include English pedagogy and American culture. 